\title{
Изменение площади и интенсивности гигантской корональной дыры
}

\author{
О.А. Андреева, В.М. Малащук, З.С. Ахтемов, Р.К. Жигалкин \\ ФГБУН “Крымская астрофизическая обсерватория РАН”, Научный, Крым, 298409 \\ olga@craocrimea.ru
}

Поступила в редакцию 14 ноября 2017 г.

\begin{abstract}
Аннотация. Исследованы изменения характеристик долгоживущей (24 кэрринтоновских оборота) гигантской корональной дыры (ГКД) в процессе ее эволюции от возникновения до исчезновения. В работе использованы наблюдения Солнца в линии Не I 1083 нм (БСТ-2 КрAО РАН), данные SDO (AIA, канал 19.3 нм, HMI, магнитные измерения). В статье представлены результаты анализа изменений таких эволюционных характеристик, как площадь и интенсивность ГКД. Проведено сравнение площади ГКД в фотосфере, полученной с помощью модельных расчетов (PFSS) с площадями, определяемыми по данным наблюдений.

VARIATIONS IN THE AREA AND INTENSITY OF THE GIANT CORONAL HOLE, by O.A. Andreeva, V.M. Malaschuk, Z.S. Akhtemov, R.K. Zhygalkin. Variations in characteristics of the long-lived (24 Carrington rotations) giant coronal hole $(\mathrm{GCH})$ have been studied in the process of their evolution from origination to extinction. In the paper we used solar observations in the HeI $1083 \mathrm{~nm}$ line (TST-2 CrAO RAS), SDO data (AIA, channel at $19.3 \mathrm{~nm}, \mathrm{HMI}$, magnetic measurements). The paper presents the results of an analysis of changes in such evolutionary characteristics as the area and intensity of GCH. A comparison is made of the GCH area in the photosphere obtained by means of model calculations (PFSS) with areas determined from observational data.
\end{abstract}

Ключевые слова: Солнце, корональные дыры, магнитное поле, эволюция

\section{1 Введение}

Корональные дыры (КД) - это крупномасштабные области короны с пониженной плотностью вещества и, по-видимому, температурой. Для КД характерна преимущественно открытая конфигурация силовых линий магнитного поля. КД наблюдаются в рентгеновском, ультрафиолетовом и микроволновом диапазонах как темные образования на солнечном диске (Калер, Хадсон, 2002) и как более яркие участки в инфракрасном излучении в линии Не I $10830 \AA$; в последнем случае область КД характеризуется также исчезновением или размытием хромосферной сетки (Степанян, Маланушенко, 2001; Зирин, 1988). КД стали объектом интенсивных исследований в начале 1970-х гг., когда выяснилось, что они являются источниками высокоскоростных потоков солнечного ветра (ВСП) (Нолт и др., 1976.; Шили, Харви, 1981). Нолт и его соавторы установили прямую зависимость между площадью КД и скоростью истекающего из нее солнечного ветра. Позднее связь КД с ВСП устанавливалась неоднократно (Гослинг, Пиццо, 1999; МакКомас, Элиот, 2002; Занг и др., 2002, 2003). 
Предположение о том, что яркость КД должна коррелировать с некоторыми характеристиками связанного с ней ВСП, в первую очередь со скоростью, было высказано около 20 лет назад в работах (Обридко и др., 2000) и с тех пор не проверялось. Другая связь, а именно корреляция скорости с площадью КД, проверялась неоднократно (Веселовский и др., 2006; Роббинс и др., 2006; Обридко и др., 2009). В частности, Роббинс и др. в 2006 году показали, что связь скорости солнечного ветра с площадью КД ухудшается в периоды высокой солнечной активности. Этого и можно было ожидать, поскольку корональные выбросы массы (KBM), не связанные прямо с КД, дают резкие всплески скорости, которые нарушают корреляцию с площадью КД (Обридко и др., 2009). Кроме того, в периоды высокой солнечной активности увеличивается роль замкнутых силовых линий, которые дают особо медленные потоки. В работе (Врснак и др., 2007а, 2007б) авторы изучали связь скорости солнечного ветра с площадью КД в относительно спокойный период с января по май 2005 г. и получили довольно высокий коэффициент корреляции 0.62 при транспортном времени 4 дня.

Настоящая работа является первой из серии работ, посвященных исследованию эволюции и влияния на околоземное пространство долгоживущей гигантской КД 2015-2017 гг. В работе приводятся результаты анализа изменений таких эволюционных характеристик, как площадь и интенсивность ГКД. Проводится сравнение площади ГКД на уровне фотосферы, полученной с помощью модельных расчетов (PFSS), с площадями, определенными из наблюдательных данных для хромосферы и короны.

\section{2 Данные и методы исследования}

Работа основана на анализе изображений полного диска Солнца, полученных в двух спектральных диапазонах: в инфракрасной линии Не I $10830 \AA$ (КрAО РАН) и в ультрафиолетовой Fe XII $193 \AA$ (SDO/AIA). Совместно с ними анализировались также данные о магнитном поле (SDO/HMI) и ре-

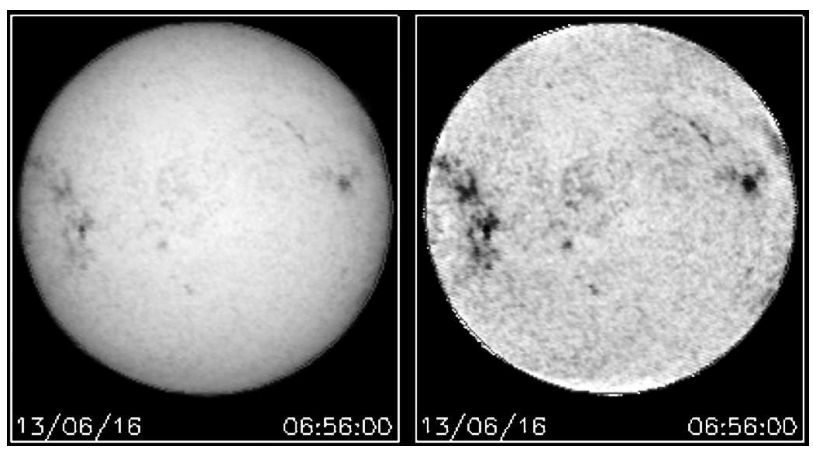

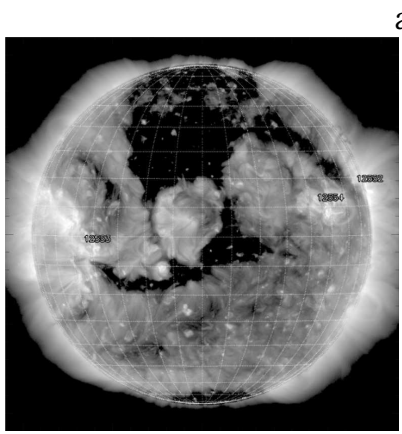

б)

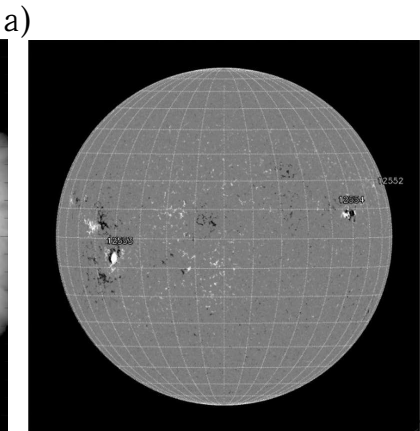

B)

Рис. 1. Изображения диска Солнца, полученные 13.06.2016 г. в инфракрасной линии Не I в КрAО PAH с учетом потемнения к краю диска (а - справа), в ультрафиолетовой Fe XII на SDO/AIA (б) и магнитограмма $\mathrm{SDO} / \mathrm{HMI}$ (в) 
зультаты модельных расчетов. Корональные дыры на изображениях Не I (рис. 1а) видны как светлые образования, а на изображениях Fe XII (рис. 1б) - как темные.

Ко всем изображениям была применена процедура предварительной обработки: для изображений в линии Не I $10830 \AA$ (Hе I) было учтено потемнение к краю и произведено нормирование яркости изображения. Изображения в линии Fe XII $193 \AA$ А (Fe XII) были приведены к масштабу изображений в линии Не I. При помощи специально разработанной нами программы Solar Data Application (SDA) для получения параметров выделенных контуров на диске Солнца были определены площади и средняя интенсивность ГКД.

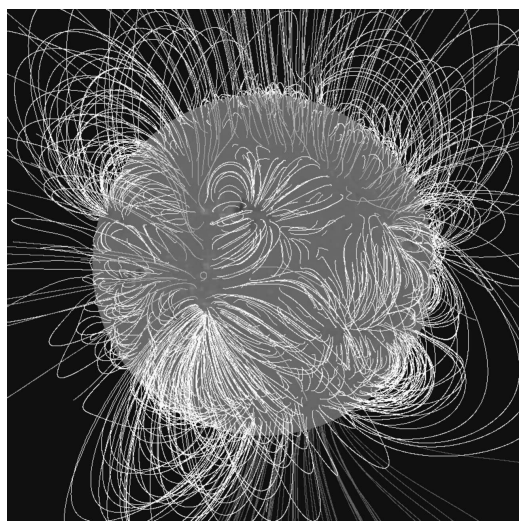

a)

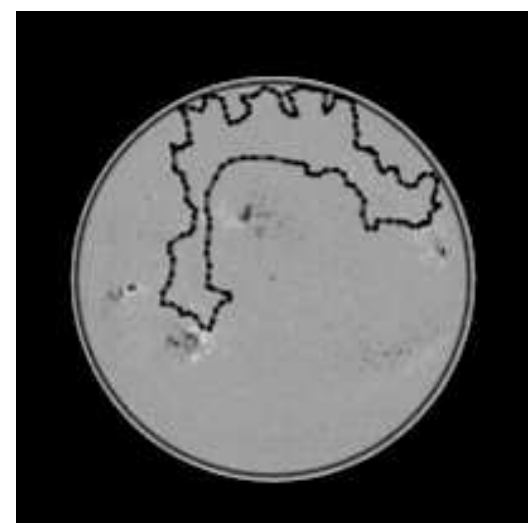

б)

Рис. 2. Результаты моделирования магнитного поля (PFSS) на уровне фотосферы по данным SDO/HMI (a) и контур КД на магнитограмме (б) за 25.02.2016 г. (CR 2174)

Для определения площади ГКД на уровне фотосферы к данным о магнитном поле (SDO/HMI) был применен пакет программ Solar Soft Potential Field Source Surface (PFSS). PFSS, в paмках потенциального приближения магнитного поля фотосферы, рассчитывает магнитное поле для высот от 1 до $2.5 \mathrm{R}_{\odot}$ где $\mathrm{R}_{\odot}$ - радиус Солнца. По силовым линиям магнитного поля, рассчитанным для уровня фотосферы $\mathrm{h}=1.0 \mathrm{R}_{\odot}(\mathrm{a})$, на магнитограмме для $\mathrm{CR} 2174$ проведены контуры ГКД (б), что позволило определить ее площадь (рис. 2).

\section{3 Изменение площади ГКд}

Появление КД на диске Солнца, которая бы занимала значительную его часть и существовала больше 2 -х десятков кэррингтоновских оборотов (CR) при регулярных наблюдениях - большая редкость. Время ее существования - 24 оборота (CR 2165 - CR 2188), что соответствует временному интервалу: июнь 2015 г. - март 2017 г.

Признаки исследуемой ГКД первоначально были обнаружены в июне 2015 г. на широте около $25^{\circ}$ (CR 2165). Через два дня, когда КД оказалась около нулевого меридиана, была определена ее площадь. В течение последующих оборотов ГКД меняла свою площадь, положение и яркость.

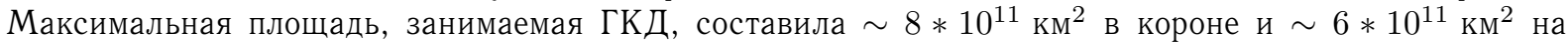
фотосфере. В максимуме своего развитии ГКД распространилась до 30 градусов южной полусферы.

Сначала нами были определены площади ГКД для верхних слоев атмосферы Солнца по изображениям, полученным в линиях He I и Fe XII. Площадь ГКД измерялась в км². Результаты представлены на рис. 3 (две верхние линии графика). 


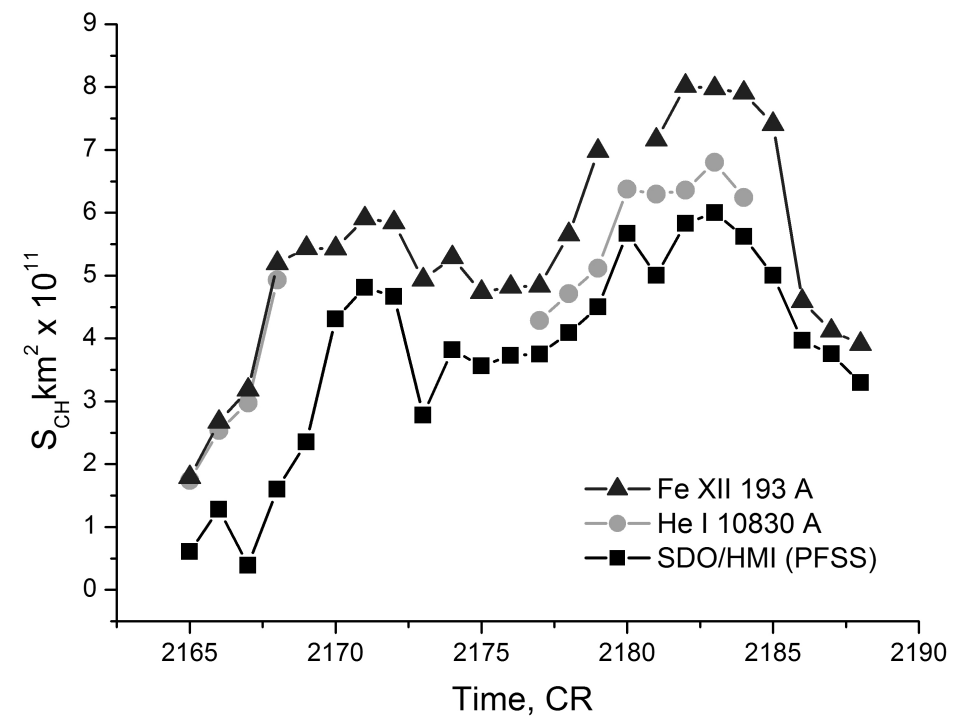

Рис. 3. Изменение площади ГКД, полученной по наблюдениям в линиях Fe XII (треугольники), Не I (кружки) и по модельному расчету в фотосфере (квадратики)

Полученные с помощью модельных расчетов площади ГКД на уровне фотосферы, нижняя кривая рис. 3, были сопоставлены с площадями, полученными по наблюдениям в хромосфере и короне. Выявлена зависимость изменения площади ГКД в процессе эволюции на 3-х высотах (рис. 3).

Эволюция ГКД имела 3 ярко выраженных этапа. В начальной стадии развития площадь КД увеличивалась как за счет изменения внешних границ, так и за счет возникновения флоккульных элементов, пор и активных областей. На стадии роста площадь ГКД на трех высотах синхронно растет. Причем на уровне хромосферы и короны разница в площадях почти неразличима.

Этап формирования ГКД в короне завершается раньше (через $4 \mathrm{CR}$ ), чем в фотосфере (через 6 CR). При этом площадь на всех уровнях существенно увеличивается, в короне и хромосфере $\sim$ в 4 раза, на фотосфере в 9 раз. Затем наступает первая стадия более-менее стабильного существования КД в короне CR 2168 - CR 2172, для фотосферы CR 2170 - CR 2172, когда площадь с флуктуациями $\sim 30 \%$ мало меняется. На уровне короны и фотосферы в изменении площади КД после CR 2172 наблюдается резкий спад, а после CR 2177 - существенное ее увеличение, определяющее вторую стадию формирования ГКД. За время существования ГКД через нее прошли 2 активных образования, что сказалось на изменении ее параметров. В течение трех оборотов (CR 2175 - CR 2177) уменьшение площади КД на уровне короны сопровождалось существенной перестройкой КД и сменой активных корональных центров. Вторая стадия сформированной КД продлилась восемь оборотов (CR 2178 CR 2185). Максимум площади здесь составил $\sim 8 * 10^{11} \mathrm{KM}^{2}$ в короне и $\sim 6 * 10^{11} \mathrm{KM}^{2}$ на фотосфере. На завершающей стадии существования KД (после CR 2185) площадь начинает резко уменьшается в короне, приближаясь к площади в фотосфере в конце (CR 2188).

\section{4 Изменение интенсивности ГКД}

В работе была исследована зависимость изменения средней интенсивности контура ГКД со временем. Интенсивность излучения в КД по наблюдениям в линиях Fe XII и Не I измеряется в относительных единицах - единицах невозмущенного диска Солнца. Для Не I эти значения менялись в пределах $1.006-1.022$, для Fe XII - в пределах 0.16-0.46. На рис. 4 показано изменение средней интенсивности ГКД на высоте в линии Fe XII за все время ее существования (24 CR). 


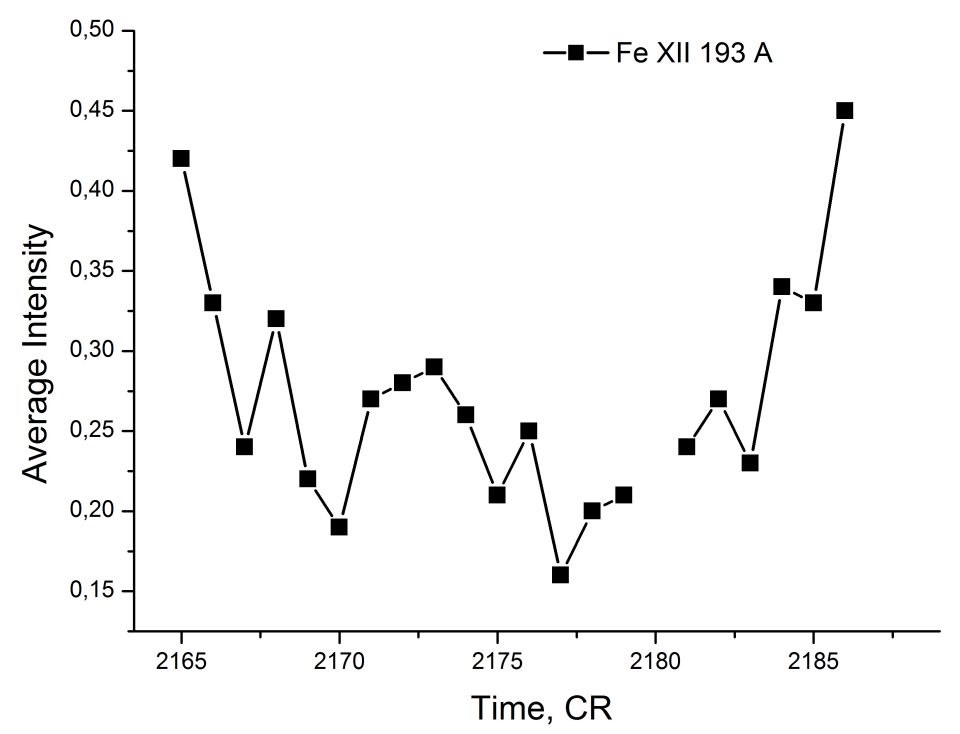

Рис. 4. Изменение средней интенсивности контура ГКД со временем за 24 CR (2015-2017), полученное по данным SDO/AIA в линии Fe XII $193 \AA$

\section{5 Выводы}

Были исследованы особенности эволюции долгоживущей ГКД от ее рождения до исчезновения. Основные результаты нашего исследования можно сформулировать следующим образом:

- Рост площади с момента зарождения ГКД составляет для короны 4 CR, 20 оборотов площадь ГКД стабилизируется, меняясь в пределах 30 \%, и 4 CR проходит от уменьшения площади ГКД до ее исчезновения. Для фотосферы эти фазы составляют соответственно 6, 13 и 5 оборотов.

- Изменения площади ГКД с середины 2015 г. по март 2017 г. происходят почти синхронно в границах, определенных по модельным расчетам PFSS на уровне фотосферы и по изображениям Солнца в линиях Не I и Fe XII.

- Средняя интенсивность КД зависит от момента ее эволюции. Она меняется от интенсивности невозмущенной области до интенсивности КД. Со временем КД становилась все темнее и темнее в линии Fе XII. Этот процесс длится примерно столько же, сколько и рост площади.

- Уменьшение интенсивности в линии Не I хорошо коррелирует с увеличением интенсивности в линии Fe XII.

- Границы ГКД, проведенные по силовыми линиям, полученным по PFSS для выбранных высот, в большинстве случаев хорошо согласуются с границами ГКД, определенными по наблюдениям интенсивностей.

Результаты этих исследований будут использованы нами далее для сопоставления с параметрами солнечного ветра и дальнейшего изучения влияния на околоземную космическую погоду.

Работа выполнена при частичной поддержке регионального гранта РФФИ № 16-42-910467 p_a.

\section{Литература}

Веселовский И.С., Персианцев И.Г., Русанов А.Ю., Шугай Ю.С. // Астрон. вестник. 2006. Т. 40. C. 427.

Врснак и др. (Vrsnak B., Temmer M., and Veronig A.M.) // Solar Phys. 2007a. V. 240. P. 315. 
Врснак и др. (Vrsnak B., Temmer M., and Veronig A.M.) // Solar Phys. 2007б. V. 240. P. 331. Гослинг, Пиццо (Gosling J.T. and Pizzo V.J.) // Space Sci. Rev. 1999. V. 89. P. 21.

Занг и др. (Zhang J., Woch J., Solanki S.K., and R. von Steiger) // Geophys. Res. Lett. 2002. V. 29. P. 1236.

Занг и др. (Zhang J., Woch J., Solanki S.K., et al.) // J. Geophys. Res. 2003. V. 108. P. 1144.

Зирин (Zirin Н.) // The Sun. New York: Cambridge University Press. 1988. P. 259.

Калер, Хадсон (Kahler S.W. and Hudson H.S.) // Astrophys. J. 2002. V. 574. P. 467.

МакКомас, Элиот (McComas D.J. and Elliot H.A.) // Geophys. Res. Lett. 2002. V. 29. P. 1314.

Нолт и др. (Nolte J.T., Krieger A.S., Timothy A.F., et al.) // Solar Phys. 1976. V. 46. P. 303.

Обридко и др. (Obridko V.N., Fomichev V.V., Kharshiladze A.F., et al.) // Astron. Astrophys. Trans. 2000. V. 18. P. 819.

Обридко В.Н., Шельтинг Б.Д. и др. // Астрон. журн. 2009. Т. 86. № 11. С. 1125.

Роббинс и др. (Robbins S., Henney C.J., and Harvey J.W.) // Solar Phys. 2006. V. 233. P. 265.

Степанян Н.Н., Маланушенко Е.В. // Изв. Крымск. Астрофиз. Обсерв. 2001. Т. 97. С. 76.

Шили, Харви (Sheeley N.R., Jr., Harvey J.W.) // Solar Phys. 1981. V. 70. P. 237. 